\title{
Structural and Magnetic Properties of As-Cast Fe-Nd Alloys
}

\author{
V.P. Menushenkov, I.V. Shchetinin, M.V. Gorshenkov and \\ A.G. Savchenko
}

\begin{abstract}
The effect of composition on the magnetic properties and microstructure of as-cast $\mathrm{Nd}-\mathrm{Fe}$ alloys was investigated. The temperature dependence of the hysteresis loops was studied. The magnetic phases with ordering temperatures in the range from 7 to $50 \mathrm{~K}$ and from 420 to $580 \mathrm{~K}$ are detected from zero-field cooled (ZFC) and field cooled (FC) dependencies of magnetization. At temperatures below $100 \mathrm{~K}$, the increase of the magnetizing field leads to a sharp increase of the magnetization, which does not saturate in the magnetization field $90 \mathrm{kOe}$. The correlations between the microstructure and coercivity of the as-cast $\mathrm{Nd}-\mathrm{Fe}$ alloys are discussed.
\end{abstract}

Keywords $\mathrm{Nd}-\mathrm{Fe}$ alloys $\cdot$ As-Cast $\cdot$ Microstructure $\cdot$ Hysteresis loop Magnetization - Coercivity

\section{Introduction}

The Nd-Fe alloys have great interest because of their important role in the sintering process and formation of $\mathrm{Nd}-\mathrm{Fe}-\mathrm{B}$ permanent magnets with large coercivity. The as-cast $\mathrm{Fe}_{16} \mathrm{Nd}_{84}$ alloy first reported by Drozzina and Janus [1] [P. 36] in 1935 had coercive force $H_{\mathrm{ci}} \approx 4,5 \mathrm{kOe}$ at room temperature (RT). High coercivity $\left(H_{\mathrm{ci}} \approx 8,6 \mathrm{kOe}\right.$ at RT and $H_{\mathrm{ci}} \approx 59 \mathrm{kOe}$ at $20 \mathrm{~K}$ ) in rapidly quenched $\mathrm{Nd}_{40} \mathrm{Fe}_{60}$ alloys was reported by Croat [2] [P. 125, 3 P 3161]. The coercive force of the as-cast $\mathrm{Nd}$-rich $\mathrm{Nd}-\mathrm{Fe}$ alloys is associated with the metastable anisotropic $\mathrm{A}_{1}$ phase which is formed during crystallization and cooling below the eutectic temperature by decomposition of the Fe-rich regions within the metastable eutectic [4] [P. 215],

\footnotetext{
V.P. Menushenkov · I.V. Shchetinin ( $\square) \cdot$ M.V. Gorshenkov · A.G. Savchenko National University of Science and Technology "MISIS", Moscow, Russia

e-mail: ingvar@misis.ru

V.P. Menushenkov

e-mail: menushenkov@gmail.com 
[5] [P. 5971], [6] [P. L1], [7] [P. 169], [8] [P. 209], [9] [P. 245], [10] [P. L5], [11] [P. 273], [12] [P. 97], [13] [P. 149], [14] [P. MM3.2.1]. Kumar [14] [P. MM3.2.1] proposed that the $A_{1}$ regions behave as an assembly of randomly oriented uniaxial $\mathrm{Nd}-\mathrm{Fe}$ clusters or nanocrystallites with the nature of single-domain particles. According to [3] [P 3161], [15] [P. 2088], [16] [P. 2302], [17] [P. 2483] high $H_{\mathrm{ci}}$ of the melt-spun $\mathrm{Fe}-\mathrm{Nd}$ alloys results from the different nonequilibrium hard magnetic phases. The size of the clusters or nanocrystallites in rapidly quenched $\mathrm{Fe}-\mathrm{Nd}$ alloys is extremely small and its composition analysis was beyond the limits of TEM capacity at the time. Despite the numerous investigations, the elucidation of the physical origin of the high coercivity in $\mathrm{Nd}-\mathrm{Fe}$ alloys is still remaining as a problem. A comparison of the microstructure and magnetic properties of the melt-spun $\mathrm{Nd}-\mathrm{Fe}$ alloys should help to clarify the origin and mechanism of the high coercivity at room and cryogenic temperatures.

In the present paper, we examine the effect of the composition of as-cast $\mathrm{Fe}_{x} \mathrm{Nd}_{100-x}(x=14-50)$ alloys on their microstructure and magnetic properties. The relationship between the coercivity and microstructure is also discussed.

\section{Experimental}

The $\mathrm{Fe}_{x} \mathrm{Nd}_{100-x}$ alloys with $x=14,28,38,50$ were arc melted under an $\mathrm{Ar}$ atmosphere. The purity of the raw materials was $\mathrm{Nd} 99.9 \%$ and $\mathrm{Fe} 99.95 \%$. The ingots were cast into a copper mold to prepare bulk samples. Magnetic measurements in the temperature range from 5 to $650 \mathrm{~K}$ were measured using a PPMS EverCool-II magnetometer in the maximum magnetizing field up to $90 \mathrm{kOe}$. The structure of the melt-spun ribbons was characterized by X-ray diffraction (XRD) using Co-K $\alpha$ radiation. The study of the microstructure was detected by a JEOL JSM-6610LV scanning electron microscope (SEM) and a JEM-1400 transmission electron microscope (TEM) operated at $120 \mathrm{kV}$. The thin foils for TEM were prepared by ion milling with Ar ions and a glancing angle of $3^{\circ}$.

\section{Results and Discussion}

The SEM images of the as-cast alloys with $x=14$ and 50 are represented in Fig. 1. The microstructures of the both the samples consist of different regions. The microstructure of $x=14$ sample consists of the $\mathrm{Nd}$ phase crystals and intergranular eutectic. The SEM image of the $x=50$ sample show the crystals of the $\mathrm{Nd}_{2} \mathrm{Fe}_{17}$ phase surrounded Nd-rich shell and intergranular eutectic phase. The composition of the phases in the alloys were measured by EDX analysis attached to the SEM.

The TEM images of the eutectic regions in the as-cast $x=14$ and 50 samples are shown in Fig. 2. The interplanar spacing $\left(\mathrm{d}_{\mathrm{HKL}}\right)$ calculated from SAED patterns of the as-cast samples $x=14(0.322,0.280,0.22,0.197,0.167,0.161,0.127,0.122$, 
(a)

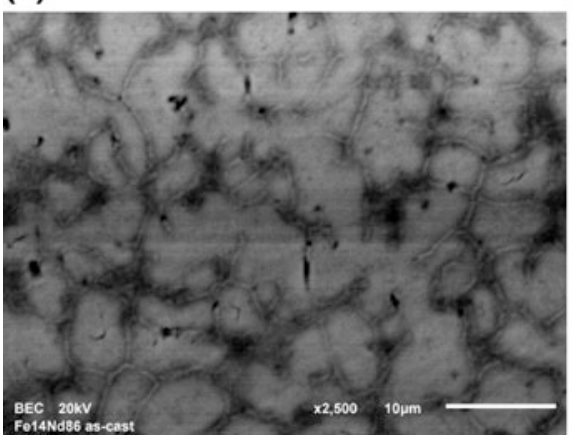

(b)

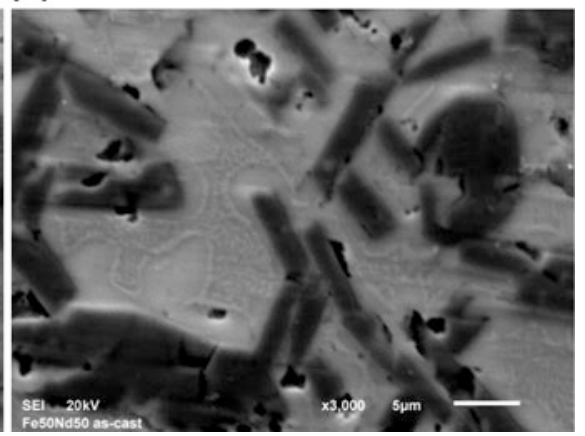

Fig. 1 SEM micrographs of the as-cast alloys $x=14$ (a) and 50 (b)

$0.112 \mathrm{~nm})$ and $x=50(0.286,0.190,0.166,0.126,0.155,0.118 \mathrm{~nm})$ correspond to the fcc phase with $a=5.5 \mathrm{~nm}$. The fcc phase was observed in melt spun Nd-Fe alloy $[7,18]$ and in as-cast Nd-Fe alloys [19, 20]. But the presence in the SAED patterns of the broadened rings with $\mathrm{d}_{\mathrm{HKL}}=0.3$ and $0.21 \mathrm{~nm}$ could be corresponded to the unknown $A_{\text {un }}$ phase. According to Fig. 2, the structure of the as-cast samples is comprised of the grains of the crystalline $\mathrm{Nd}$ along with amorphous-like regions. The amorphous-like regions in turn consists of nanocrystals of the $A_{\text {un }}$ phase embedded in amorphous matrix.

The hysteresis loops for the $x=14$ and 50 as-cast samples are shown in Fig. 3. The hysteresis loop of the as-cast alloys $x=14,28$ (Fig. 3a, b) and $x=32,50$ (Fig. 3c, d) differ significantly. First, the as-cast alloys $x=14,28$ have at RT a high coercive force $H_{\mathrm{ci}}=4,7$ and 4,3 kOe, respectively. The alloys $x=32,50$ have low coercive force $H_{\mathrm{ci}}=2,4$ and $0,1 \mathrm{kOe}$, respectively. Second, in the as-cast alloys $x=14,28$ during the temperature decrease from 300 to $100 \mathrm{~K}$ the value of $\mathrm{M}_{\mathrm{r}}$ is maintained, but the width of the hysteresis loops continuously increases along the $X$ axis, that resulting in the growth of coercive force up to $28 \mathrm{kOe}(x=14)$ and $37 \mathrm{kOe}(x=28)$ after magnetization in a field of $50 \mathrm{kOe}$. However, at temperatures below $100 \mathrm{~K}$, a sharp increase of the magnetization (3-4 times) in strong external fields is observed, which is followed by a decrease in coercive force.

In the as-cast alloys $x=38,50$ during the temperature decrease from 300 to $100 \mathrm{~K}$ the coercive force practically does not change and remains low $\left(H_{\mathrm{ci}}=2,4\right.$ and $0,1 \mathrm{kOe}$, respectively), but the $M_{\mathrm{S}}$ continuously increases and the hysteresis loops have a constricted shape. Low remanence and coercive force of the $x=38$ and 50 alloys are the result of the presence in their structure of the soft magnetic $\mathrm{Nd}_{2} \mathrm{Fe}_{17}$ phase, the amount of which exceeds $50 \%$ (Fig. 1). The amount of $\mathrm{Nd}_{2} \mathrm{Fe}_{17}$ phase was calculated from the SEM images. It can also be assumed that the reason for the expansion of the hysteresis loop at higher fields is the resistance of the spin moments rotation of Nd-based phases, which are ferromagnetic below $50 \mathrm{~K}$ and provide a sharp increase of the magnetic moment in a field $H \geq 50 \mathrm{kOe}$. At a temperature below $100 \mathrm{~K}$, the magnetization of the $x=14$ and 28 ribbons do not reach saturation in the field as high as $90 \mathrm{kOe}$. 
Fig. 2 TEM micrographs of the as-cast $x=14$ (a) and 50 (b) samples. Darkfield image from the intergranular region 1 , taken in first ring reflection (c) and SAED patterns of the intergranular region 1 (d) and crystalline region 2 (e). The scale bar in Fig. 2a is $1 \mu \mathrm{m}$
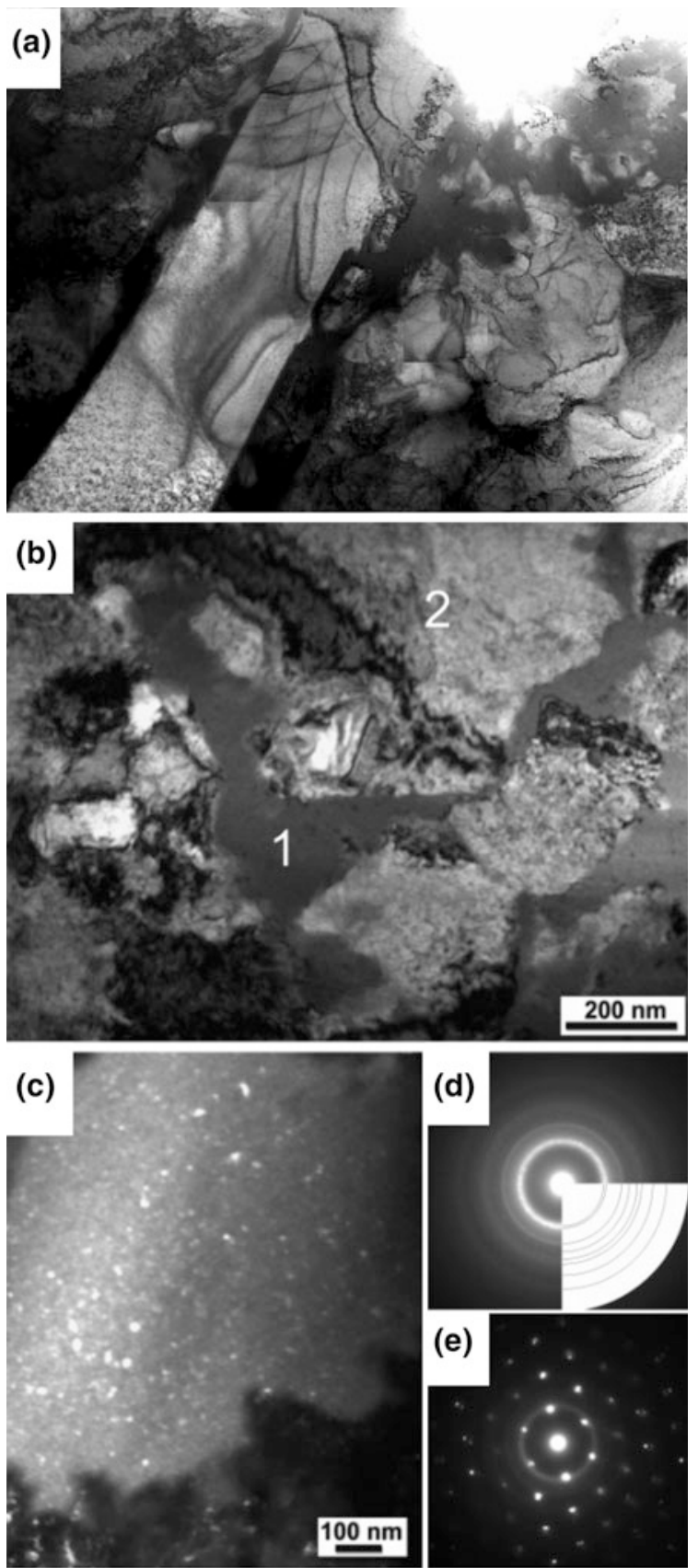

(d)

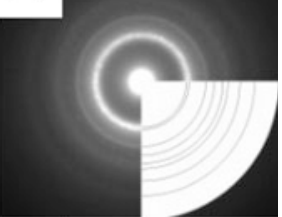

(e)

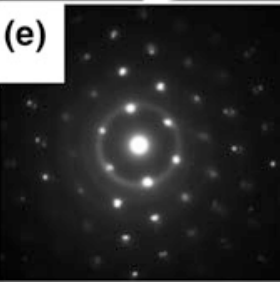


Fig. 3 The temperature dependence of $M$ for the as-cast $\mathrm{Fe}_{x} \mathrm{Nd}_{100-x}$ samples with $x=14-50$
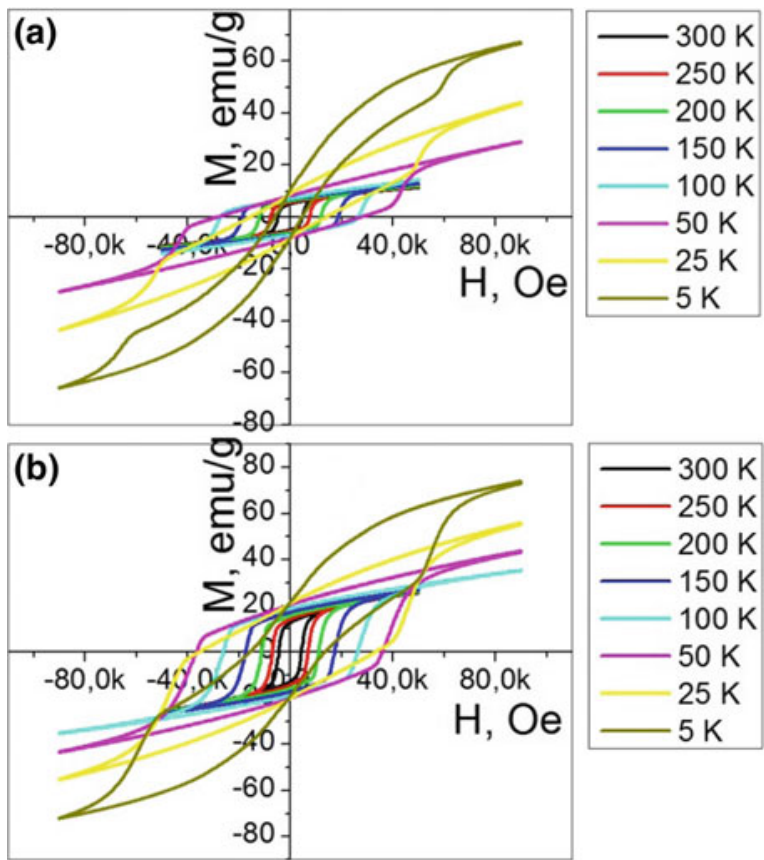
$200 \mathrm{~K}$ $150 \mathrm{~K}$ $100 \mathrm{~K}$ $50 \mathrm{~K}$ $25 \mathrm{~K}$
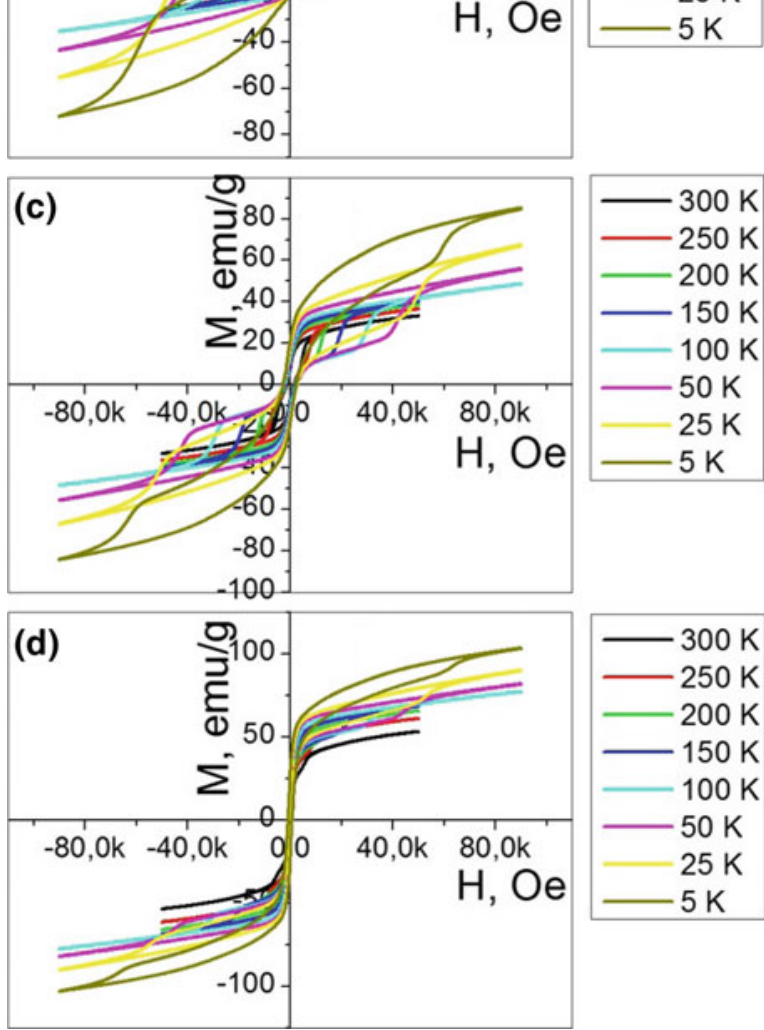
$250 \mathrm{~K}$ $200 \mathrm{~K}$ $150 \mathrm{~K}$ $100 \mathrm{~K}$ $50 \mathrm{~K}$ $25 \mathrm{~K}$ $5 \mathrm{~K}$ 
Figure 4 shows a ZFC and FC thermomagnetic curves for the as-cast $x=14-28$ samples, taken in $H=0.5 \mathrm{kOe}$ operating field in the temperature range from 5 to $350 \mathrm{~K}$. Insert (b) shows the initial part of the $\mathrm{M}(\mathrm{T})$ curves on a large scale. Three magnetic transitions take place at about $T_{1} \approx 7 \mathrm{~K}, T_{2} \approx 17 \mathrm{~K}$ and $T_{3} \approx 33 \mathrm{~K}$, respectively, indicating the presence of low-temperature magnetic phases. The data in Fig. 4 allow to assume that the bend of $\mathrm{M}(\mathrm{T})$ at around $T_{1} \approx 7 \mathrm{~K}$ and $17 \mathrm{~K}$ corresponds to the antiferromagnetic ordering temperature of the dhcp $\mathrm{Nd}$ (the onset of ordering on cubic sites and hexagonal sites, respectively). Curie temperatures at around $33 \mathrm{~K}$ may be connected with the fcc allotropic of Nd [21] [P. 1260].

The thermomagnetic curves $\mathrm{M}(\mathrm{T})$ in Fig. 5 measured at a temperature higher than $300 \mathrm{~K}$ show the ordering temperature at around $550 \mathrm{~K}$. These high-temperature

(a)

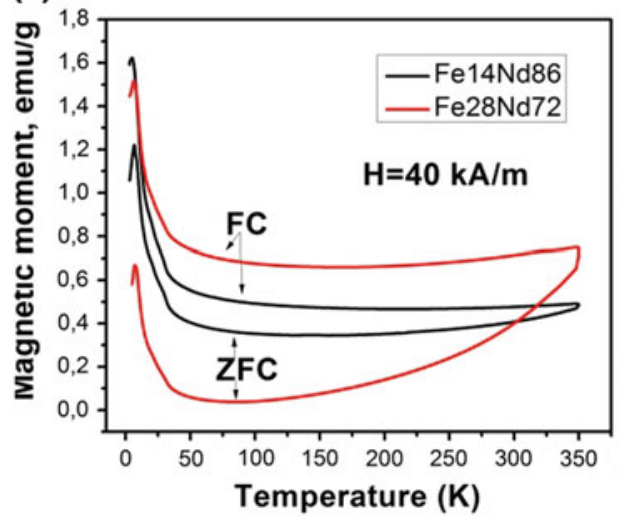

(b)

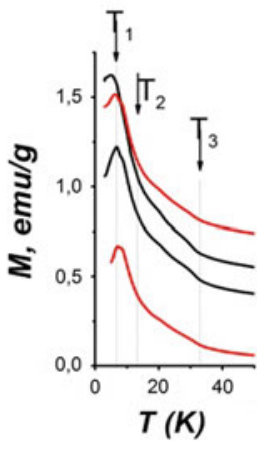

Fig. 4 Thermomagnetic zero-field cooled (ZFC) and field cooled (FC) dependencies of $M$ for the as-cast $x=14$ and 28 samples measured in $H=0.5$ kOe operating field

Fig. 5 Termomagnetic zero-field cooled (ZFC) and field cooled (FC) dependencies of $M$ for the as-cast $x=14-50$ samples measured in $H=40 \mathrm{kA} / \mathrm{m}$ operating field

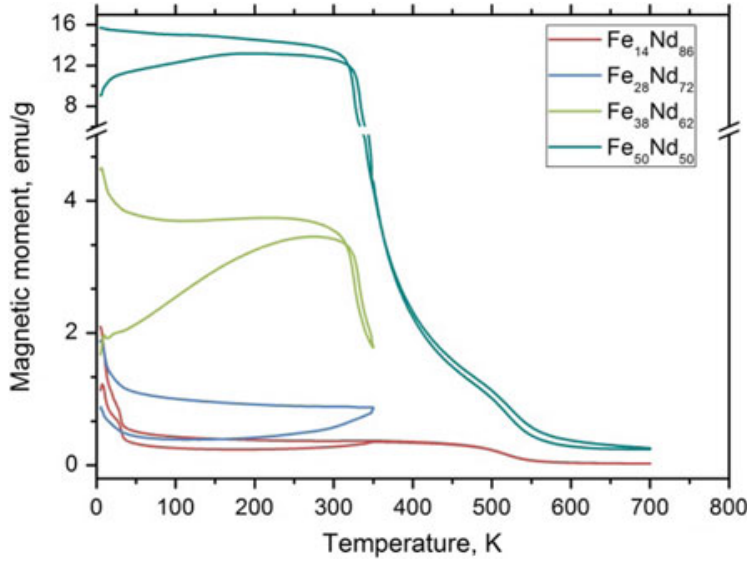


ferromagnetic-paramagnetic transitions should be attributed to the well-known metastable highly anisotropic $A_{1}$ phase which is associated with the high coercivity of the as-cast Nd-Fe alloys at RT. Due to the presence of these magnetic phases the magnetization of the $\mathrm{Nd}-\mathrm{Fe}$ ribbons and as-cast alloys does not saturate in highest magnetization field $90 \mathrm{kOe}$ at temperatures below $100 \mathrm{~K}$.

The temperature dependence of coercive force for the $x=14$ and 28 ribbons from 50 to $300 \mathrm{~K}$ is shown in Fig. 6a. As in the case of the melt-spun alloys, the temperature dependence shows a linear relationship between $H_{\mathrm{ci}}^{1 / 2}$ and $T^{2 / 3}$ in the temperature range 50-300 $\mathrm{K}$ for the samples $x=14$ and 28 (Fig. 6b).

These data also demonstrate a good agreement with strong pinning model of domain walls, proposed by Gaunt [22] [P. 261]. The coercivity of the as-cast samples both at room temperature and at lower temperatures may be associated with a domain wall pinning on the nanocrystals inside amorphous-like regions. However, the cause of the high coercivity at temperatures below $50 \mathrm{~K}$ is still not clear, since at these temperatures the nanocrystals of $\mathrm{Nd}$-rich phase are ferromagnetic.

Fig. 6 The temperature dependence of $H_{\mathrm{ci}}$ (a) and $\left(H_{\mathrm{ci}}\right)^{1 / 2}$ as a function of $(T)^{2 / 3}$ (b), for as-cast $\mathrm{Fe}_{x} \mathrm{Nd}_{100-x}$ $(x=14-28)$ samples over the temperature range $50-300 \mathrm{~K}$
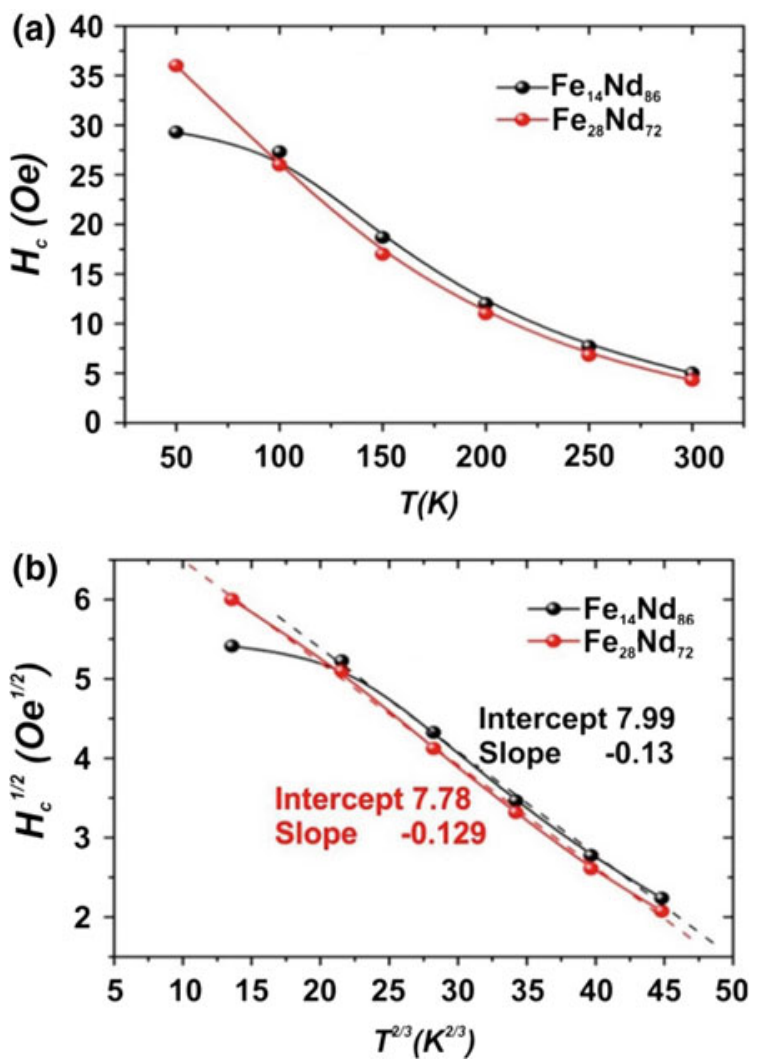


\section{Conclusion}

The comparison of the $\mathrm{Fe}_{x} \mathrm{Nd}_{100-x}$ alloys, prepared by crystallization in the mold, allowed revealing the influence of the composition on the microstructure and properties of the synthesized alloys.

The coexistence of some magnetic phases with ordering temperatures below $50 \mathrm{~K}$ takes place in as-cast $\mathrm{Nd}-\mathrm{Fe}$ alloys. The curves of $\mathrm{M}(\mathrm{T})$ at around $7 \mathrm{~K}$ and $17 \mathrm{~K}$ corresponds to the antiferromagnetic ordering temperature of the dhcp $\mathrm{Nd}$ (the onset of ordering on cubic sites and hexagonal sites, respectively). Curie temperature at around $33 \mathrm{~K}$ may be connected with the fcc allotropic of $\mathrm{Nd}$, and $T_{\mathrm{C}} \approx 47 \mathrm{~K}$ may be related to the magnetic transition of the Nd-rich nanocrystals.

The strong pinning model of domain walls can describe the temperature dependence of coercive force of the as-cast alloys in the temperature range $50-250 \mathrm{~K}$, but the cause of the high coercivity at temperatures below $50 \mathrm{~K}$ is still not clear.

Acknowledgements Research are carried out with the financial support of the state represented by the Ministry of Education and Science of the Russian Federation. Agreement (contract) no. 14.575.21.0043 27 Jun 2014. Unique project Identifier: RFMEFI57514X0043.

\section{References}

1. Drozzina, V., Janus, R.: A new magnetic alloy with very large coercive force. Nature $\mathbf{1 3 5}$, 36-37 (1935)

2. Croat, J.J.: Crystallization and magnetic properties of melt-spun neodymium-iron alloys. J. Magn. Magn. Mater. 24, 125-131 (1981)

3. Croat, J.J.: Magnetic hardening of Pr-Fe and Nd-Fe alloys by melt-spinning. J. Appl. Phys. 53 (4), 3161-3169 (1982)

4. Schneider, G., Martinek, G., Stadelmaier, H.H., Petzow, G.: High magnetic coercivity due to a new phase in cast eutectic Fe-Nd alloys. Mater. Lett. 7, 215-218 (1988)

5. Tsoukatos, A., Strzeszewski, J., Hadipanayis, G.: High coercivities in as-cast Nd-Fe and Nd-Fe-Ti alloys. J. Appl. Phys. 64, 5971-5973 (1988)

6. Hadipanayis, G., Tsoukatos, A., Strzeszewski, J., Long, G.J., Pringle, O.A.: A new hard magnetic phase in binary Nd-Fe and Pr-Fe alloys. J. Magn. Magn. Mater. 78, L1-L5 (1989)

7. Schneider, G., Landgraf, F.J.G., Missell, F.P.: Additional ferromagnetic phases in the Fe-Nd-B system and the effect of $600^{\circ} \mathrm{C}$ annealing. J. Less. Common Met. 153, 169-180 (1989)

8. Landgraf, F.J.G., Schneider, G., Villas-Boas, V., Missell, F.P.: Solidification and solid state transformations in Fe-Nd: revised phase diagram. J. Less-Comm. Met. 163, 209-218 (1990)

9. Moreau, J.M., Paccard, L., Nozieres, J.P., Missell, F.P., Schneider, G., Villas-boas, V.: A new phase in the Nd-Fe system: Crystalline structure of $\mathrm{Nd}_{5} \mathrm{Fe}_{17}$. J. Less. Comm. Met. 163, 245251 (1990)

10. Givord, D., Nozieres, J.P., Rossignol, M.F., Tailor, D.W., Harris, I.R., Fruchart, D., Miraglia, S.: Structural analysis of the hard ferromagnetic phase observed in quenched Nd-Fe alloys of hyper-eutectic composition. J. Alloys Comp. 176, L5-L11 (1991)

11. Delamare, J., Lemarch, D., Vigier, P.: Structural investigation of the metastable compound A1 in an as-cast Fe-Nd eutectic alloy. J. Alloys Comp. 216, 273-280 (1994) 
12. Menushenkov, V.P., Anderson, S.J., Hoier, R.: Electron-microscopy investigations of microstructure in Fe-Nd alloys, Proc. of the 20-th Int. Symposium on Magnetic Anisotropy and Coercivity in Rare-Earth Transition Metal Alloys, edited by L. Schultz and K.-H. Müller, Werkstoff-Infromationsgesellschaft, Frankfurt, pp. 97-106 (1998)

13. Menushenkov, V.P., Lileev, A.S., Oreshkin, M.A., Zhuravlev, S.A.: Metastable nanocrystalline A1 phase and coercivity in Fe-Nd alloys. J. Magn. Magn. Mater. 203, 149-152 (1999)

14. Kumar, G., Kerschl, P., Rößler, U.K., Nenkov, K., Müller, K.-H., Schultz, L.: TEM and XAS characterization of hard magnetic phase in Fe-Nd alloys, Mat. Res. Soc Simp. Proc. 806, MM3.2.1-MM.3.2.6 (2004)

15. Sellmyer, D.J., Ahmed, A., Muench, G., Hadjipanayis, G.: Magnetic hardening in rapidly quenched Fe-Pr and Fe-Nd alloys. J. Appl. Phys. 55(6), 2088-2090 (1984)

16. Siratori, K., Nagayama, K., Ino, H., Saitoii, N., Nakagawa, Y.: Appearance of high-coercivity in Fe-Nd amorphous alloys, IEEE Trans. Magn., Vol. MAG-23, 2302-2304 (1987)

17. Nagayama, K., Ino, H., Saito, N., Nakagawa, Y., Kita, E., Siratori, K.: Magnetic properties of amorphous Fe-Nd alloys. J. Phys. Soc. Japan 39(7), 2483-2495 (1990)

18. Menushenkov, V.P., Shchetinin, I.V., Gorshenkov, M.V., Savchenko, A.G., Ketov, S.V.: Microstructure and magnetic properties of melt-spun Nd-rich Nd-Fe alloys, IEEE Magn. Let. 7 (2016). doi:10.1109/LMAG.2015.2512980

19. Liao, L.X., Altaunian, Z., Ryan, D.H.: Formation of high presure phases in rapidly quenched Fe-Nd alloys. J. Appl. Phys. 67, 4821-4823 (1990)

20. Menushenkov, V.P., Gabay, A.M., Lileev, A.S., Obrucheva, E.V., Jalnin, B.V.: Magnetic properties and structure of hydrogenated Nd-Fe alloys. J. Alloys Comp. 209, 299-304 (1994)

21. Bucher, E., Chu, C.W., Maita, J.P., Andres, K., Cooper, A.S., Buehler, E., Nassau, K.: Electronic properties of two new elemental ferromagnets: fcc Pr and Nd. Phys. Rev. Lett. 22, 1260-1263 (1969)

22. Gaunt, P.: Ferromagnetic domain wall pinning by a random array of inhomogeneties. Philos. Mag. B 48, 261-276 (1983)

Open Access This chapter is licensed under the terms of the Creative Commons Attribution 4.0 International License (http://creativecommons.org/licenses/by/4.0/), which permits use, sharing, adaptation, distribution and reproduction in any medium or format, as long as you give appropriate credit to the original author(s) and the source, provide a link to the Creative Commons license and indicate if changes were made.

The images or other third party material in this book are included in the chapter's Creative Commons license, unless indicated otherwise in a credit line to the material. If material is not included in the chapter's Creative Commons license and your intended use is not permitted by statutory regulation or exceeds the permitted use, you will need to obtain permission directly from the copyright holder.

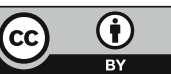

